\title{
Use of Marker-assisted Selection to Breed for Resistance to Common Bacterial Blight in Common Bean
}

\author{
Patrick D. O'Boyle and James D. Kelly ${ }^{1}$ \\ Department of Crop and Soil Sciences, Michigan State University, East Lansing, MI 48824-1325 \\ William W. Kirk \\ Department of Plant Pathology, Michigan State University, East Lansing, MI 48824-1325
}

\begin{abstract}
AdDitional InDEX words. CBB, dry beans, MAS, quantitative trait locus, multiplex PCR, Phaseolus vulgaris, Xanthomonas campestris pv. phaseoli

ABSTRaCT. Common bacterial blight (CBB), incited by the bacterial pathogen Xanthomonas axonopodis pv. phaseoli (Smith) Vauterin et al., is one of the most serious seed-borne diseases of common bean (Phaseolus vulgaris L.) worldwide. Although previous attempts to breed CBB-resistant bean cultivars have had limited success due to the quantitative nature of resistance, progress in marker-assisted selection has created new opportunities for breeders to improve the selection process. The potential of independent linked markers for indirect selection of CBB resistance was evaluated in field experiments in East Lansing and Saginaw, Mich. The presence of the SU91 marker was correlated with lower CBB leaf scores in East Lansing $(r=-0.50 * * *)$ and Saginaw $(r=-0.59 * * *)$ and correlated with pod resistance in Saginaw $\left(r=-0.48^{* * *}\right)$. SU91 exhibited a slight negative correlation with yield $\left(r=-0.20^{*}\right)$ in East Lansing but showed no association with yield in Saginaw. Plant selections carrying SU91 were crossed with a different source of $\mathrm{CBB}$ resistance linked to the sequence-characterized amplified region marker BC420 on bean linkage group B6. The effects of SU91 and BC420 markers were examined in two greenhouse studies. The presence of SU91 was correlated with lower CBB disease ratings for leaves $(r=-0.20 *)$ and pods $(r=-0.27 * * *)$. Presence of BC420 was only correlated with low pod ratings $\left(r=-0.19^{*}\right)$ in one experiment and CBB leaf resistance $\left(r=-0.18^{*}\right)$ in the second experiment. Presence of both markers resulted in lower levels of CBB resistance than provided by either marker alone, possibly indicating epistatic interactions between the independent loci conditioning $\mathrm{CBB}$ resistance in common bean.
\end{abstract}

Common bacterial blight (CBB) is one of the most serious production problems of common bean (Phaseolus vulgaris) worldwide (Tar'an et al., 2001). CBB is a seed-borne disease incited by the bacterial pathogen Xanthomonas axonopodis pv. phaseoli (Xap) and is often responsible for significant yield losses and entire crop failures (Vakili et al., 1975). The most severe yield losses typically occur in years when routine daytime temperatures exceed $30{ }^{\circ} \mathrm{C}$ (Kelly and Copeland, 1996; Saettler, 1989).

The seed-borne nature of CBB is a major constraint in commercial bean production and one that has greatly influenced the location of the common bean seed production industry in the United States (Kelly and Copeland, 1996). In the midwestern United States, where CBB severity can be high, production of certified common bean seed is not economical for producers and has resulted in the displacement of previously successful seed-production programs (Anderson et al., 1970). Incorporation of CBB resistance into high-yielding commercial common bean cultivars would greatly benefit growers and seed producers in the midwestern United States by allowing them access to locally produced certified disease-free seed.

Seeds infected with Xap are regarded as the primary source of inoculum and frequently initiate epidemics in established dry bean fields (Jung et al., 1997). Xap has demonstrated a

Received for publication 21 Aug. 2006. Accepted for publication 26 Jan. 2007. We thank Veronica Vallejo, James Hancock, and Jennifer Wagner for their critical review of the manuscript.

${ }^{1}$ Corresponding author. E-mail: kellyj@msu.edu. capability to survive for extended periods in bean seed, possibly up to 10 years (Zaumeyer and Thomas, 1957). Secondary inoculum is disseminated throughout fields by wind-driven rain and soil particles, by farm implements, and human or animal passage through wet bean fields. Although standard diseasemanagement practices, such as planting disease-free seed, bactericide treatment, crop rotation, and deep-plowing, have reduced CBB epidemics, these control measures are generally inadequate (Anderson et al., 1970; Zaumeyer and Thomas, 1957). Development of resistant cultivars is needed to prevent the outbreak of severe CBB infections in commercial bean fields (Singh and Munoz, 1999).

CBB resistance in common bean is a quantitatively inherited trait that exhibits low to moderate heritability and is controlled by an unknown number of genes (Coyne and Schuster, 1974a). Musaana et al. (1993) determined that the number of genes associated with resistance to CBB varied depending on the parents used in population development and on the stage at which the plants were evaluated. The CBB resistance sources used in their study were PI 207262, IAPAR 16, and BAC 6. Leaf resistance was controlled by one to three genes at an early growth stage and by one to four genes later in maturity, and pod resistance was conditioned by one to two genes. The presence of additive gene effects for CBB resistance has been reported, while other studies have suggested incomplete dominant gene action. Coyne and Schuster (1974b) determined that CBB resistance was dominant in a cross between GN 1140 (susceptible parent) and PI 207262 (resistant parent) and that a small number of genes controlled the resistant reaction. Because 
the level of resistance to CBB reported in $P$. vulgaris is limited, resistance sources present in the related species Phaseolus acutifolius L. (tepary bean) and Phaseolus coccineus L. (scarlet-runner bean) have been identified and used in bean breeding programs. The development of gene pyramids consisting of resistance from various genetic backgrounds has been suggested as the most effective strategy for the development of CBB-resistant cultivars (Singh and Munoz, 1999).

Breeding for genetic resistance to $\mathrm{CBB}$ in common bean is hindered by the complex genetic nature of the host resistance. Although bean genotypes with $\mathrm{CBB}$ resistance have been identified, the resistance is partial and does not provide complete protection from pathogen infection (Park et al., 1999). A further complication of quantitative disease resistance is that the genetic loci involved are subject to environmental influence (Mutlu et al., 2005). The expression of quantitative resistance in contrasting genetic backgrounds or environmental conditions may vary and complicate breeding efforts. In addition, the differential response of plant organs to $\mathrm{CBB}$ infection and a lack of correlation in reaction to CBB between leaves, pods, and seeds further complicate breeding for resistance (Arnaud-Santana et al., 1994).

The substantial progress made in molecular marker technology for the common bean holds considerable promise for breeding genetic resistance to CBB (Kelly et al., 2003; Miklas et al., 2006). Molecular markers allow breeders to avoid direct screening techniques that may be less effective in selection of quantitative traits that are significantly affected by environmental factors. Markers linked to several quantitative trait loci (QTL) might be useful tools in breeding for CBB resistance; however, their efficiency in new genetic backgrounds requires testing before use (Miklas et al., 2000; Singh and Munoz, 1999). The P. acutifolius-derived QTL examined in this research are two independent QTL linked to the sequencecharacterized amplified region (SCAR) markers BC420 and SU91 that map to bean linkage groups B6 and B8, respectively (Miklas et al., 2000). Although CBB resistance conferred by known QTL is partial, the availability of molecular markers allows distinct QTL to be screened and consequently provides an opportunity to pyramid multiple QTL for CBB resistance into a single bean genotype.

The objectives of this research were 1) to examine the potential for using previously developed molecular markers linked to $\mathrm{CBB}$ resistance in a marker-assisted selection (MAS) strategy; 2) to determine the effects on $\mathrm{CBB}$ resistance of previously discovered QTL in genetic backgrounds differing from the initial genotypes in which they were discovered; and 3 ) to determine the potential for combining multiple sources of CBB resistance into a single genotype (QTL pyramiding).

\section{Materials and Methods}

Parental materials and population development. The resistant parents (99L91-45 and 99L91-47) initially used for the development of $\mathrm{CBB}$ resistant populations were developed from VAX 5, a breeding line developed at CIAT (International Center for Tropical Agriculture, Cali, Columbia) from an interspecific hybridization between $P$. vulgaris and $P$. acutifolius (Singh and Munoz, 1999). VAX 5 has resistance derived from both XAN 159 and GN Nebraska \#1 Sel. 27, two of the most widely used sources of CBB resistance. The Michigan State University black bean ( $P$. vulgaris) breeding line B98311 was crossed with VAX 5 to develop two locally adapted breeding lines (99L91-45 and 99L91-47) that carry the SU91 marker and CBB resistance derived from VAX 5. The phenotypic reaction of 99L91-45 and 99L91-47 in response to CBB infection is similar to that of VAX 5 (Table 1). These breeding lines were crossed with a commercial cultivar, Phantom (Kelly et al., 2000), and elite breeding lines (N99219, B98306, and $\mathrm{B} 00136)$ to combine $\mathrm{CBB}$ resistance with favorable agronomic characteristics (Frahm, 2002). In total, eight $F_{2}$ populations were selected for advancement via the single-seed descent (SSD) breeding method (Johnson and Bernard, 1962). A group of $30 \mathrm{~F}_{5}$ lines were selected from the SSD-derived populations based on marker genotype and agronomic traits. These 30 selections included 15 lines that carried SU91 and 15 lines that did not possess the marker. The 30 selected $\mathrm{F}_{5}$ lines were grown as $\mathrm{F}_{5: 6}$ lines in the replicated field studies in East Lansing and Saginaw, Mich.

To combine resistance sources, a group of $15 \mathrm{~F}_{5}$ black and $15 \mathrm{~F}_{5}$ navy bean ( $P$. vulgaris) lines that carried the SU91 marker were selected from the aforementioned populations and crossed with either Phantom*2/SEL 1308 or Jaguar*2/SEL 1308 breeding lines to introduce the $\mathrm{Co}-4^{2}$ gene for resistance to anthracnose, another serious seed-borne disease of common bean. The resulting $F_{1}$ progeny were used in four-way crosses with $\mathrm{F}_{1}$ plants of the cross HR45/Kaboon. HR45 is the donor parent of the BC420 QTL for CBB resistance (Park and Dhanvantari, 1994; Yu et al., 2000), and 'Kaboon' carries the

Table 1. Comparison of mean leaf and pod common bacterial blight (CBB) ratings and seed yield between 15 lines of common bean with $\left(\mathrm{SU}^{+} 1^{+}\right)$and 15 lines without $\left(\mathrm{SU91}{ }^{-}\right)$the SCAR marker SU91, plus checks and parents from field plots grown at East Lansing and Saginaw, Mich., in 2003.

\begin{tabular}{lcccc}
\hline Location & SU91 $^{\mathrm{z}}$ & $\begin{array}{c}\text { Leaf } \\
(1-9 \text { scale })^{\mathrm{y}}\end{array}$ & $\begin{array}{c}\text { Pod } \\
(0-3 \text { scale })^{\mathrm{x}}\end{array}$ & $\begin{array}{c}\text { Seed yield } \\
\left(\mathrm{Mg} \cdot \mathrm{ha}^{-1}\right)\end{array}$ \\
\hline East Lansing & + & 3.43 & 0.98 & 2.05 \\
Checks & - & 4.49 & 1.11 & 2.20 \\
$\quad$ Midland & - & 7.46 & 2.03 & 1.53 \\
Othello & - & 5.99 & 0.67 & 2.18 \\
VAX 5 & + & 3.06 & 1.08 & 2.18 \\
HR-45 & + & 2.30 & 0.89 & 1.65 \\
99L91-45 & + & 3.03 & 1.22 & 2.00 \\
99L91-47 & + & 3.34 & 0.92 & 2.17 \\
LSD $_{0.05}{ }^{\mathrm{w}}$ & & $0.39^{*}$ & 0.14 & $0.39^{*}$ \\
Saginaw $^{\mathrm{v}}$ & + & 4.67 & 0.53 & 3.08 \\
& - & 6.56 & 1.05 & 2.96 \\
LSD $_{0.05}$ & & $0.64^{*}$ & $0.23^{*}$ & 0.37 \\
\hline
\end{tabular}

z"+" represents the class of genotypes that carry the SCAR marker SU91; "-" represents the class of genotypes that do not carry the SCAR marker SU91.

${ }^{\mathrm{y}}$ Mean CBB leaf ratings (evaluated 13 and $20 \mathrm{~d}$ after the final inoculation) in East Lansing in 2003. Leaf ratings were recorded on a $1-9$ scale, with $1=$ uninfected and $9=$ severe necrotic regions.

${ }^{\mathrm{x}}$ Mean CBB pod ratings (13 and $20 \mathrm{~d}$ after the final inoculation) in East Lansing in 2003. Pod ratings were recorded on a $0-3$ scale, with $0=$ uninfected and $3=$ severe pod infection.

wFisher's least-significant difference at $P>0.05\left(\mathrm{LSD}_{0.05}\right)$.

vonly one CBB leaf rating and one CBB pod rating were taken at the Saginaw location. This experiment was not inoculated; natural infection was sufficient for screening.

${ }^{*}$ Significance at the $0.05 P$ level. 
Co- $1^{2}$ gene for resistance to anthracnose. Single-plant selections were made in the $\mathrm{F}_{2}$ populations in Saginaw in 2002, and a total of $320 \mathrm{~F}_{2: 3}$ lines were grown as single-row plots in East Lansing during Summer 2003, where 93 single-plant selections were made based on adaptation. The greenhouse study on the effect of pyramiding BC420 and SU91 QTL was conducted on the same set of $93 \mathrm{~F}_{3: 4}$ single-plant selections from the East Lansing field plots.

Molecular MAS. SCAR markers used in selection for $\mathrm{CBB}$ resistance were dominant, scored as the presence or absence of a single band on an agarose gel. The PCR protocol used was described by Melotto et al. (1996) except Invitrogen Taq polymerase was used (Invitrogen, Carlsbad, Calif.). Both previously developed SCAR markers used in screening (SU91 and $\mathrm{BC} 420$ ) are dominant and are derived independently from resistant tepary bean germplasm. SU91 is linked to a QTL for CBB resistance on bean linkage group B8. BC420 is linked to a QTL for $\mathrm{CBB}$ resistance on bean linkage group B6 (Miklas et al., 2000; Pedraza et al., 1997; Yu et al., 2000).

PCR results were analyzed using a $1.4 \%$ agarose gel stained with ethidium bromide $\left(0.02 \mu \mathrm{g} \cdot \mathrm{mL}^{-1}\right)$. Bands present on the gel were compared by size to a 100-bp ladder (Invitrogen). When multiplex PCR was used, SU91 (700 bp) and BC420 (900 bp) were distinguishable by size using ultraviolet light fluorescence. For multiplex PCR, the reaction conditions for the SAP6 SCAR marker was used (Miklas et al., 2000) because it has an annealing temperature intermediate to that of SU91 and BC420. The PCR profile was 34 cycles of $10 \mathrm{~s}$ at $94{ }^{\circ} \mathrm{C}$, $40 \mathrm{~s}$ at $55^{\circ} \mathrm{C}, 2 \mathrm{~min}$ at $72{ }^{\circ} \mathrm{C}$, and $5 \mathrm{~min}$ at $72{ }^{\circ} \mathrm{C}$ for the final extension. For each multiplex reaction, the components were present in the concentrations suggested by Melotto et al. (1996) with the following exceptions: $1.5 \mu \mathrm{L}\left(10 \mathrm{ng} \cdot \mu \mathrm{L}^{-1}\right)$ of each primer and $16.35 \mu \mathrm{L} \mathrm{H}_{2} \mathrm{O}$ were used.

Field AND GREENHOUSE INOCULATIONS AND DISEASE EVALUATion. Field plots were established at the Agronomy Farm of Michigan State University in East Lansing on 27 May 2003. Field plots at the Saginaw Valley Bean and Beet Research Farm were established on 2 June 2003. All plots were band-fertilized at planting with $46 \mathrm{~kg} \cdot \mathrm{ha}^{-1}$ of $19 \mathrm{~N}-$ $8.3 \mathrm{P}-15.8 \mathrm{~K}$. Weeds were controlled with an application of $0.38 \mathrm{~L} \cdot \mathrm{ha}^{-1}$ ethafluralin and $0.25 \mathrm{~L} \cdot \mathrm{ha}^{-1}$ metolachlor before planting. Plots were sprayed with $0.19 \mathrm{~L} \cdot \mathrm{ha}^{-1}$ dimetholate for insect control as needed during the growing season.

The field plots at East Lansing included three replications, each of which included a block of 12 rows of the susceptible cultivar Midland to facilitate the spread of the pathogen. Field plots were inoculated with a Xap solution $\left(10^{6} \mathrm{cfu} / \mathrm{mL}\right)$ of the isolate 9712-3 (obtained from the University of Nebraska) on 16 and 24 July 2003. This isolate was originally obtained from an infected Michigan seed source of the cultivar Tomahawk and is equivalent in virulence to the LB-2 isolate from the University of Nebraska (J. Reiser, personal communication). A power sprayer was used to apply the inoculum at $\approx 1.03 \mathrm{MPa}$ until water-soaking was observed and upper leaf surfaces were completely covered with inoculum. Leaf disease reaction was evaluated on 6 and 13 Aug. 2003 using a scale of 1 to $9(1=$ no visible disease symptoms, $9=$ very severe disease symptoms with $>25 \%$ of the leaf surface displaying lesions), described by van Schoonhoven and Pastor-Corrales (1987). Pod disease reaction was observed on the same dates and was recorded on a scale of 0 to $3(0=$ no pod lesions, $3=$ more than eight distinct pod lesions). Other traits evaluated in the field plots included days to flowering (at least $50 \%$ of plants in a plot have one or more open flowers), lodging (based on a 1-5 scale: $1=$ no lodging, $5=$ extensive lodging), height (in $\mathrm{cm})$, maturity (recorded as the number of days after planting at which the plot was ready for harvest), and seed weight (in g).

Greenhouse experiments were conducted at Michigan State University. Plants were grown in 15.2-cm-diameter clay pots with sterile potting soil used as growth medium. Slow-release fertilizer was added to each pot at the primary leaf stage, and plants were watered as needed. Inoculation experiments consisted of four replications, each composed of $93 \mathrm{~F}_{3: 4}$ individuals selected from the $320 \mathrm{~F}_{2: 3}$ lines in the field in addition to four control genotypes of known phenotypic reaction to CBB inoculation. The resistant controls were HR45 and VAX 5 and the susceptible controls were 'Midland' and 'Othello'. The four control genotypes were included twice as inoculated and non-inoculated controls in each replication, for a total of 101 entries per replication.

The greenhouse inoculations were conducted twice using the basic procedure described by Andrus (1948); for each inoculation, the trifoliate leaves were also inoculated twice. The first inoculation was conducted when all plants had at least one flower, and the second inoculation was 1 week later. Leaves were evaluated for visual symptoms $7 \mathrm{~d}$ after inoculation in the first experiment and $14 \mathrm{~d}$ after inoculation in the second experiment. Two pods were inoculated per plant during the flat pod stage of development. Pods were inoculated once and were evaluated for disease reaction $14 \mathrm{~d}$ after inoculation.

EXPERIMENTAL DESIGN AND STATISTICAL ANALYSIS. Analysis of variance (ANOVA) was determined for each experiment using the PROC GLM function of SAS (SAS Institute, Cary, N.C.). Traits showing association $(P>0.05)$ with BC420 or SU91 based on $F$ values of single-factor analysis of variance (ANOVA) were analyzed using Fisher's protected least significant difference (LSD), with $a=0.05$. The PROC REG function of SAS was used for regression analysis of all traits, and $r$ values were determined.

\section{Results}

USE OF SCAR MARKer SU91 In MAS. The first and second leaf ratings for resistance to $\mathrm{CBB}$, taken at 13 and $20 \mathrm{~d}$ after inoculation, were significantly different between $\mathrm{SU}^{+}{ }^{+}$and SU91 $^{-}$genotypic classes $(P<0.0001)$ in the East Lansing field experiment. The mean leaf rating for $\mathrm{SU}^{+}{ }^{+}$lines was 3.43 compared with mean leaf rating of 4.49 for the $\mathrm{SU}^{-} 1^{-}$lines (Table 1). No significant differences were detected between genotypic classes in the two pod ratings for $\mathrm{CBB}$ resistance ( $P=0.09$ and $P=0.052$, respectively). The presence of SU91 was significantly associated with both leaf $(P<0.0001)$ and pod $(P<0.0001)$ phenotypic disease ratings in the Saginaw field experiment, where only one rating was recorded. The SU91 ${ }^{+}$ genotypes had a mean leaf disease rating of 4.67 , compared with a mean of 6.56 for those lines without SU91. The mean pod disease ratings were 0.53 and 1.05 for $\mathrm{SU}^{+}{ }^{+}$and $\mathrm{SU} 91^{-}$lines, respectively. Interestingly, among the 10 lines that showed the highest level of phenotypic $\mathrm{CBB}$ resistance at each location, $70 \%$ carried SU91 in the East Lansing experiment, while 100\% of the lines carried SU91 in the Saginaw experiment (Table 1).

The occurrence of linkage drag has been demonstrated in prior breeding efforts for CBB resistance (Valladares-Sanchez et al., 1979), therefore the presence of SU91 was assessed to 
determine whether it had a negative effect on seed yield or other important agronomic traits in beans grown at East Lansing and Saginaw. The association between the presence of SU91 and yield reduction at the East Lansing location was significant $(P=0.02$; Table 1$)$; however, no association was observed at the Saginaw location where high-yielding lines with enhanced levels of $\mathrm{CBB}$ resistance were identified $(P=0.08)$. Of the 10 lines carrying SU91, seven yielded significantly higher than the mean seed yield of the test in East Lansing. Maturity and seed weight were not significantly associated with the presence of SU91 at either location (data not shown).

Evaluation of CBB Resistance QTL in a Different GENETIC BACKGROUND. Field and greenhouse inoculations were used in combination to evaluate the effects of QTL for $\mathrm{CBB}$ resistance in a genetic background differing from the initial genotypes in which they were identified. The effects of the SU91 QTL were tested in field experiments, while both SU91 and BC420 were tested in greenhouse inoculation experiments. SU91 was significantly associated with both leaf and pod resistance in greenhouse experiments, although the phenotypic correlation was not as strong as was observed in field conditions (Table 2). There was a significant negative correlation between SU91 and leaf resistance in greenhouse experiment $1\left(r=-0.18^{*}\right)$ and greenhouse experiment $2\left(r=-0.15^{* *}\right)$. In addition, SU91 was correlated with $\mathrm{CBB}$ pod resistance in experiment $1\left(r=-0.17^{*}\right)$ and experiment $2(r=-0.27 * * *)$. In contrast, $\mathrm{BC} 420$ was associated with only pod resistance in experiment $1\left(r=-0.19^{*}\right)$ and $\mathrm{CBB}$ leaf resistance in experiment 2 ( $r=-0.18^{*}$; Table 2$)$.

Pyramiding of QTL fOR CBB Resistance. Molecular marker technology allows the possibility of combining multiple QTL for a trait-of-interest in a single genotype. Greenhouse inoculations were used to analyze the disease resistance of common bean genotypes possessing both BC420 and SU91. Both SCAR markers were associated with leaf and pod resistance to $\mathrm{CBB}$ independently in field and greenhouse experiments. The mean $\mathrm{CBB}$ leaf rating for bean genotypes lacking either SCAR marker was 4.4, whereas the mean CBB leaf ratings for genotypes carrying SU91 or BC420 were 2.6 and 2.5, respectively. The mean CBB leaf rating (3.4) for both markers together was higher than the mean disease rating for either marker alone and failed to provide additional levels

Table 2. Phenotypic correlation coefficients for the presence of SCAR markers SU91 and BC420 with leaf and pod reaction to CBB in two greenhouse inoculation experiments with 101 entries of common bean.

\begin{tabular}{lccccc}
\hline & \multicolumn{2}{c}{ Greenhouse: expt. 1 } & & \multicolumn{2}{c}{ Greenhouse: expt. 2 } \\
\cline { 2 - 3 } \cline { 5 - 6 } Marker $^{z}$ & CBB-leaf $^{\mathrm{y}}$ & CBB-pod & & CBB-leaf & CBB-pod \\
\hline SU91 & $-0.18^{* *}$ & $-0.17^{*}$ & & $-0.15^{* *}$ & $-0.27^{* * *}$ \\
BC420 & 0.06 & $-0.19^{*}$ & & $-0.18^{* *}$ & -0.06
\end{tabular}

${ }^{\mathrm{z}} \mathrm{SU} 91$ is a SCAR marker linked to a CBB-resistance QTL on bean linkage group B8. BC420 is a SCAR marker linked to a CBBresistance QTL on bean linkage group B6.

${ }^{y} \mathrm{CBB}-$ Leaf and CBB-Pod refer to visual CBB ratings based on a $1-9$ scale for leaves $(1=$ no symptoms, $9=$ severe symptoms $)$ and a $0-3$ scale for pods $(0=$ no symptoms, $3=$ severe symptoms $)$. Phenotypic correlation coefficients $(r)$ are presented between the SCAR markers and the visual disease ratings.

${ }^{*, * *, * * *}$ Significant at the $5 \%, 1 \%$, and $0.1 \%$ probability levels, respectively. of $\mathrm{CBB}$ resistance over that of the individual markers. In contrast, the mean $\mathrm{CBB}$ pod rating for the single marker classes, SU91 or BC420, was equivalent to the mean CBB pod rating for the combination of both markers in the same genotype (Table 3).

\section{Discussion}

Resistance to $\mathrm{CBB}$ in common bean is a quantitative trait that exhibits low to moderate heritability and should be an excellent candidate for MAS ( $\mathrm{Yu}$ et al., 2000). However, several factors must be considered for MAS to be useful in a breeding program. QTL-marker associations may be population specific and the usefulness of a marker in selecting for the quantitative trait must be verified in other populations (Dudley, 1993; Yu et al., 2000). Because previous research has indicated a potential for linkage drag associated with CBB resistance (Valladares-Sanchez et al., 1979), the possibility of linkage between $\mathrm{CBB}$ resistance and unfavorable agronomic traits must be examined before the development of a successful MAS program.

This study examined the association between the SU91 marker and $\mathrm{CBB}$ field resistance to address the situation of population specificity of marker-trait associations and to determine if the source of $\mathrm{CBB}$ resistance was significantly associated with undesirable agronomic traits (Beebe, 1989; Valladares-Sanchez et al., 1979). On the basis of field experiments at two locations in 2003, the presence of the SCAR marker SU91 was clearly associated with high levels of CBB leaf resistance in both locations in addition to $\mathrm{CBB}$ pod resistance in one of the two locations. The SU91 marker was weakly correlated with lower seed yields in the East Lansing study, but yield reduction was under 7\%. Regardless, highyielding SU91 ${ }^{+}$lines with high levels of field CBB resistance were observed. No such correlation was evident for the Saginaw location, where yields were higher and disease pressure was greater (Table 1). The presence of SU91 was not associated with any of the other agronomic traits (days to flowering, lodging, height, maturity, and seed weight) examined.

Observation of yield drag associated with $\mathrm{SU}^{+}{ }^{+}$in East Lansing may indicate a yield penalty incited by the presence of the QTL under low disease pressure. The CBB resistance conferred by SU91 may have obscured this negative effect in environments where the disease pressure was higher. Yield comparison of these lines in the complete absence of the disease would help determine whether the presence of SU91 is

Table 3. Comparison of the mean CBB leaf and pod ratings of two greenhouse experiments for SCAR marker combinations in $93 \mathrm{~F}_{3: 4}$ lines of common bean.

\begin{tabular}{lccc}
\hline $\begin{array}{l}\text { Marker } \\
\text { combination }\end{array}$ & $\begin{array}{c}\text { Genotypes } \\
\text { (no.) }\end{array}$ & $\begin{array}{c}\text { Leaf } \\
(1-9 \text { scale })^{\mathrm{z}}\end{array}$ & $\begin{array}{c}\text { Pod } \\
(1-9 \text { scale })^{\mathrm{z}}\end{array}$ \\
\hline$-/-$ & 6 & $4.4 \mathrm{a}$ & $3.7 \mathrm{a}$ \\
SU91+/- & 54 & $2.6 \mathrm{~b}$ & $2.3 \mathrm{~b}$ \\
$-/$ BC420+ & 3 & $2.5 \mathrm{~b}$ & $1.8 \mathrm{~b}$ \\
SU91+/BC420+ & 30 & $3.4 \mathrm{c}$ & $2.0 \mathrm{~b}$
\end{tabular}

${ }^{\mathrm{z}}$ Mean ratings are averages of 4 replications, determined using 1-9 scales for leaves and pods ( $1=$ no symptoms, $9=$ severe symptoms $)$. Separation of means, designated by different letters, was determined using Fisher's protected least-significant difference at $P>0.05$ $\left(\mathrm{LSD}_{0.05}\right)$. 
associated with linkage drag in these genotypes. However, the association between SU91 and reduced yield was weak, and high-yielding common bean lines with both SU91 and improved $\mathrm{CBB}$ resistance were identified.

Resistance to $\mathrm{CBB}$ in common bean is a quantitative trait, and, as a result, the level of resistance conferred by a single QTL is partial (Jung et al., 1996; Nodari et al., 1993). Developing breeding lines with pyramided QTL from various resistance sources could help increase the levels of partial resistance beyond that conferred by a single QTL (Castro et al., 2003). A recent study by Mutlu et al. (2005) examined the pyramiding of multiple QTL for CBB resistance into a single pinto bean ( $P$. vulgaris) genotype. The results from that study differed from those observed in this study in that the combination of multiple QTL for CBB resistance provided a higher level of resistance than that conferred by either QTL alone. A direct comparison of results between the two studies is not possible because Mutlu et al. (2005) examined several molecular markers linked to QTL for CBB resistance and did not specifically examine the combination of SU91 and BC420 in the absence of other QTL for resistance. Additionally, they found that the BC420 marker provided a significant level of resistance, but the use of this marker is not practical in certain market classes as it is linked to the $V$ locus that results in an undesirable darker seedcoat color (Miklas et al., 2006; Mutlu et al., 2005). Even though the combination of SU91 and BC420 in a single genotype was not associated with increased levels of $\mathrm{CBB}$ resistance in the greenhouse experiments in this study, both markers were independently associated with leaf and pod resistance to $\mathrm{CBB}$. The failure of the combination of both markers to provide elevated levels of resistance may suggest some type of epistatic interaction of these QTL in a common disease-resistance pathway or the uneven distribution of marker genotypes in the study.

Although use of MAS will not completely eliminate the need for direct phenotypic selection for CBB resistance, MAS can be used to reduce the number of lines that require direct screening. Including only $\mathrm{SU}^{+} 1^{+}$or $\mathrm{BC} 420^{+}$genotypes in field and greenhouse screening will increase the possibility of selecting highly CBB-resistant genotypes while minimizing the number of inoculations conducted and space required for screening. The contribution of the QTL linked to these molecular markers was confirmed in a breeding population with favorable agronomic traits. The results from this study indicate a minimal effect of linkage drag that did not prevent the identification of adapted, high-yielding bean lines with improved levels of $\mathrm{CBB}$ resistance.

\section{Literature Cited}

Anderson, A.L., L.O. Copeland, and A.W. Saettler. 1970. Grow blightfree field beans. Mich. State Univ. Coop. Ext. Serv. Ext. Bul. 680.

Andrus, C.F. 1948. A method of testing beans for resistance to bacterial blight. Phytopathology 38:757-759.

Arnaud-Santana, E., D.P. Coyne, K.M. Eskridge, and A.K. Vidaver. 1994. Inheritance, low correlations of leaf, pod, and seed reactions to common blight disease in common beans; and implications for selection. J. Amer. Soc. Hort. Sci. 119:116-121.

Beebe, S.E. 1989. Quantitative genetics in Phaseolus vulgaris: the example of resistance to Xanthomonas campestris pv. phaseoli, $\mathrm{p}$. 213-238. In: S. Beebe (ed.). Current topics in breeding of common bean. Proc. Intl. Bean Breeding Wkshp. Working Document No. 47. International Center for Tropical Agriculture, Cali, Colombia.
Castro, A.J., X. Chen, A. Corey, T. Filichkina, P.M. Hayes, C. Mundt, K. Richardson, S. Sandoval-Islas, and H. Vivar. 2003. Pyramiding and validation of quantitative trait locus (QTL) alleles determining resistance to barley stripe rust: effects on adult plant resistance. Crop Sci. 43:2234-2239.

Coyne, D.P. and M.L. Schuster. 1974a. Inheritance and linkage relations of reaction to Xanthomonas phaseoli (E.F. Smith) Dowson (common blight), stage of plant development and plant habit in Phaseolus vulgaris L. Euphytica 23:195-204.

Coyne, D.P. and M.L. Schuster. 1974b. Differential reaction of pods and foliage of beans (Phaseolus vulgaris) to Xanthomonas phaseoli. Plant Dis. Rept. 58:278-282.

Dudley, J.W. 1993. Molecular markers in plant improvement: manipulation of genes affecting quantitative traits. Crop Sci. 33: 660-668.

Frahm, M.A. 2002. Effects of terminal drought stress on black beans. Mich. State Univ., East Lansing, MS Thesis.

Johnson, H.W. and R.L. Bernard. 1962. Soybean genetics and breeding. Adv. Agron. 14:149-221.

Jung, G., D.P. Coyne, P.W. Skroch, J. Nienhuis, E. Arnaud-Santana, J. Bokosi, H.M. Ariyarathne, J.R. Steadman, J.S. Beaver, and S.M. Kaeppler. 1996. Molecular markers associated with plant architecture and resistance to common blight, web blight, and rust in common beans. J. Amer. Soc. Hort. Sci. 121:794-803.

Jung, G., P.W. Skroch, D.P. Coyne, J. Nienhuis, E. Arnaud-Santana, H.M. Ariyarathne, S.M. Kaeppler, and M.J. Bassett. 1997. Molecularmarker-based genetic analysis of tepary bean-derived common bacterial blight resistance in different developmental stages of common bean. J. Amer. Soc. Hort. Sci. 122:329-337.

Kelly, J.D. and L.O. Copeland. 1996. Status of common bacterial blight problems in Michigan dry beans, p. 173-177. In: Taller Internacional sobre Bacteriosis Comun del Frijol. 1st ed. Oficina de Coordinacion Regional de Profrijol, San Cristobal, Dominican Republic.

Kelly, J.D., G.L. Hosfield, G.V. Varner, M.A. Uebersax, and J. Taylor. 2000. Registration of 'Phantom' black bean. Crop Sci. 40:572.

Kelly, J.D., P. Gepts, P.N. Miklas, and D.P. Coyne. 2003. Tagging and mapping of genes and QTL and molecular marker-assisted selection for traits of economic importance in bean and cowpea. Field Crops Res. 82:135-154.

Melotto, M., L. Afanador, and J.D. Kelly. 1996. Development of a SCAR marker linked to the $I$ gene in common bean. Genome 39: 1216-1219.

Miklas, P.N., J.R. Smith, R. Riley, K.F. Grafton, S.P. Singh, G. Jung, and D.P. Coyne. 2000. Marker-assisted breeding for pyramided resistance to common bacterial blight in common bean. Annu. Rpt. Bean Improvement Coop. 43:39-40.

Miklas, P.N., J.D. Kelly, S.E. Beebe, and M.W. Blair. 2006. Common bean breeding for resistance against biotic and abiotic stresses: from classical to MAS breeding. Euphytica 147:105-131.

Musaana, S.M., O.D. Mwandemele, and J.A. Kapuya. 1993. The number of genes controlling resistance in beans to common blight. Annu. Rpt. Bean Improvement Coop. 36:156-157.

Mutlu, N., P. Miklas, J. Reiser, and D. Coyne. 2005. Backcross breeding for improved resistance to common bacterial blight in pinto bean (Phaseolus vulgaris L.). Plant Breed. 124:282287.

Nodari, R.O., S.M. Tsai, P. Guzman, R.L. Gilbertson, and P. Gepts. 1993. Toward an integrated linkage map of common bean. III. Mapping genetic factors controlling host-bacteria interactions. Genetics 134:341-350.

Park, S.J. and B.N. Dhanvantari. 1994. Registration of common bean blight-resistant germplasm, HR45. Crop Sci. 34:548.

Park, S.O., D.P. Coyne, N. Mutlu, G. Jung, and J.R. Steadman. 1999. Confirmation of molecular markers and flower color associated with QTL for resistance to common bacterial blight in common beans. J. Amer. Soc. Hort. Sci. 124:519. 
Pedraza, F., G. Gallego, S. Beebe, and J. Tohme. 1997. Marcadores SCAR y RAPD para la resistencia a la bacteriosis comun (CBB), p. 130-134. In: S.P. Singh and O. Voysest (eds.). Taller de Mejoramiento de Frijol para el Siglo XXI: bases para una estrategia para America Latina. International Center for Tropical Agriculture, Cali, Colombia.

Saettler, A.W. 1989. Common bacterial blight, p. 261-283. In: H.F. Schwartz and M.A. Pastor-Corrales (eds.). Bean production problems in the tropics. 2nd ed. International Center for Tropical Agriculture, Cali, Colombia.

Singh, S.P. and C.G. Munoz. 1999. Resistance to common bacterial blight among Phaseolus species and common bean improvement. Crop Sci. 39:80-89.

Tar'an, B., T.E. Michaels, and K.P. Pauls. 2001. Mapping genetic factors affecting the reaction to Xanthomonas axonopodis pv. phaseoli in Phaseolus vulgaris L. under field conditions. Genome 44:1046-1056.
Vakili, N.G., W.J. Kaiser, J.E. Perez, and A. Cortes-Monllor. 1975. Bacterial blight of beans caused by two Xanthomonas pathogenic types from Puerto Rico. Phytopathology 65:401-403.

Valladares-Sanchez, N.E., D.P. Coyne, and M.L. Schuster. 1979. Differential reaction of leaves and pods of Phaseolus germplasm to strains of Xanthomonas phaseoli and transgressive segregation for tolerance from crosses of susceptible germplasm. J. Amer. Soc. Hort. Sci. 104:648-654.

van Schoonhoven, A. and M.A. Pastor-Corrales. 1987. Standard system for the evaluation of bean germplasm. International Center for Tropical Agriculture, Cali, Colombia.

Yu, K., S.J. Park, and V. Poysa. 2000. Marker-assisted selection of common beans for resistance to common bacterial blight: efficacy and economics. Plant Breed. 119:411-415.

Zaumeyer, W.J. and H.R. Thomas. 1957. Bacterial diseases of major importance, p. 65-88. In: W.J. Zaumeyer and H.R. Thomas (eds.). A monographic study of bean diseases and methods for their control. U.S. Dept. Agr., Washington, D.C. 